\title{
Effect of reclaimed water effluent on bacterial community structure in the Typha angustifolia L. rhizosphere soil of urbanized riverside wetland, China
}

\author{
Xingru Huang ${ }^{1,2}$, Wei Xiong ${ }^{4}$, Wei Liu ${ }^{1,2}$, Xiaoyu Guo ${ }^{1,2,3, *}$ \\ 1. College of Resources Environment and Tourism, Capital Normal University, Beijing 100048, China. E-mail: huangxingru@126.com \\ 2. Beijing Municipal Key Laboratory of Resources Environment and GIS, Beijing 100048, China \\ 3. Urban Environmental Processes and Digital Modeling Laboratory, Beijing 100048, China \\ 4. Research Center for Eco-Environmental Sciences, Chinese Academy of Sciences, Beijing 100085, China
}

\section{A R T I C L E I N F O}

Article history:

Received 24 February 2016

Revised 16 May 2016

Accepted 2 June 2016

Available online 4 August 2016

Keywords:

Reclaimed water

T-RFLP

16S rRNA gene clone library

Bacterial community structure

\begin{abstract}
A B S T R A C T
In order to evaluate the impact of reclaimed water on the ecology of bacterial communities in the Typha angustifolia L. rhizosphere soil, bacterial community structure was investigated using a combination of terminal restriction fragment length polymorphism and 16S rRNA gene clone library. The results revealed significant spatial variation of bacterial communities along the river from upstream and downstream. For example, a higher relative abundance of $\gamma$-Proteobacteria, Firmicutes, Chloroflexi and a lower proportion of $\beta$-Proteobacteria and $\varepsilon$-Proteobacteria was detected at the downstream site compared to the upstream site. Additionally, with an increase of the reclaimed water interference intensity, the rhizosphere bacterial community showed a decrease in taxon richness, evenness and diversity. The relative abundance of bacteria closely related to the resistant of heavy-metal was markedly increased, while the bacteria related for carbon/nitrogen/phosphorus/sulfur cycling wasn't strikingly changed. Besides that, the pathogenic bacteria markedly increased in the downstream rhizosphere soil since reclaimed water supplement, while the possible plant growth-promoting rhizobacteria obviously reduced in the downstream sediment. Together these data suggest cause and effect between reclaimed water input into the wetland, shift in bacterial communities through habitat change, and alteration of capacity for biogeochemical cycling of contaminants.
\end{abstract}

(C) 2016 The Research Center for Eco-Environmental Sciences, Chinese Academy of Sciences. Published by Elsevier B.V.

\section{Introduction}

Centralized reclaimed water treatment plants (RWTPs) are one of the most common systems for the treatment of domestic wastewater in highly urbanized areas with high population densities in Beijing, China. Therefore, RWTPs effluent represents a significant component of the supplement water of river ecosystems in Beijing. Currently, the use of reclaimed water in Beijing amounts to $2.3 \times 10^{8} \mathrm{~m}^{3}$, $1.5 \times 10^{8} \mathrm{~m}^{3}(65.2 \%)$ of which are used by lakes and rivers. However, numerous studies have documented that reclaimed water is rich in nitrogen, phosphorus and other nutrients; also, as a result of the slow stream flow of urban rivers, their long update cycle, and the single body of water ecosystem structure, the water column potentially has a higher risk of eutrophication and temporary oxygen deficits (Zhou et al.,

\footnotetext{
* Corresponding author. E-mail: xiaoyucnu@126.com (Xiaoyu Guo).
} 
2006; Meng et al., 2011). In addition, domestic wastewater is normally anthropogenic, such as municipal and hospital producing wastewater, which contains residual Pharmaceutical and Personal Care Products (PPCPs), and biologically active metabolites. These contaminants can mix into the natural water cycle through reclaimed water supplement (Yu et al., 2011; Tong and Wei, 2012; Knapp et al., 2012). Reclaimed water was one of the chlorine sources, which could produce organic pollutant, substitution reactions, disinfection byproducts, chloroform, carbon tetrachloride, etc. Thus, reclaimed water is an important source of water transmitted antibiotics and cross resistance genes from disinfection byproduct, which result in higher potential risk to human health (Dong et al., 2010).

The quality of reclaimed water affects the functions and biological processes of receiving river directly (Wassen et al., 1992), particularly when it enters waterways during periods of low natural flow. The urban artificial wetland, considered as a natural alternative to technical methods of wastewater treatment, which can effectively remove nitrogen, phosphorus, heavy metals oxide, various organic substances and pathogens, and reduce BOD and TSS content in water (Thurston et al., 2001; Zhao et al., 2007). Thus, urban artificial wetlands have gradually been widely used in improving water quality in urban lake and river landscapes (Cui et al., 2011). Many studies had pointed out that the interaction matrix, aquatic plants and microorganisms in the wetland system was the main mechanisms of effluent purification (Toyama et al., 2009). Among them, microorganisms play an imperative role in the process of purification, especially the plant rhizosphere bacteria. Wetland plants had a special ability called the "rhizosphere effect," which allows microbes in the plant rhizosphere to enhance the carrying capacity of constructed wetlands (Xiang et al., 2004). The rhizosphere bacterial communities propagate at high speed, with high abundances and strong metabolizing abilities (Feng et al., 2012), which play a very important role in the processes of removing, fixing and conversion of nitrogen, phosphorus and other organic/inorganic matters, including heavy metal removal, etc. (Jing and Yang, 2004; Zhang et al., 2007; Nicomrat et al., 2008; Li, 2012). Therefore, rhizosphere bacterial communities are the main force involved in the degradation of pollutants and play an important role in maintaining the ecological balance and achieving ecological purification of wetland systems. Characteristics of microbial biomass, activity and community composition in constructed wetlands can be directly affected by hydraulic conditions, wastewater properties, including substrate and nutrient quality and availability, filter material or soil type, plants, and other environmental factors (Truu et al., 2009). Therefore, wetland plant rhizosphere microbial characteristics can sensitively reflect the status of plant and water quality, which are considered ideal indicators of aquatic ecosystems and have been extensively used to assess the degree of toxicity imposed by various pollutants. To the best of our knowledge, most studies have focused on the impacts of wastewater treatment plants (WWTPs) effluent on bacterial communities in the water column and sediment of receiving river (Wakelin et al., 2008; Drury et al., 2013). But few studies have investigated wetland plant rhizosphere bacteria community under reclaimed water disturbance condition.
We aimed to characterize the effect of RWTPs effluent on the structure of bacterial communities in the rhizosphere bacterial community of Typha angustifolia L. in urbanized riverside wetland in our study. A combination of terminal restriction fragment length polymorphism (T-RFLP) and 16S rRNA library technique was used to investigate the diversity, abundance and function of bacterial community in T. angustifolia rhizosphere samples collected from near the reclaimed water outfall, $300 \mathrm{~m}$ upstream the RWTP outfall and $2000 \mathrm{~m}$ downstream the RWTP outfall. The two methods exhibit different properties in the analysis of community structure. T-RFLP which is widely applied to the fields of biodiversity analysis and comparison of microbial community has crucial theoretical meaning and practical applied value (Wang et al., 2012). However, it is not applicable to describe community composition because of some shortcomings. For example, phylogenetic identification is problematic because some terminal restriction fragments (T-RTs) can't match the corresponding species or genus of bacteria from database (Marsh, 1999). Conversely, the 16S rRNA clone library method is not suitable for analyses of community diversity since the limitation of conversion efficiency. However, for community composition analysis, the 16S rRNA clone library method, which has the highest resolution ability, appears to be suitable (Guo et al., 2015). Narrowleaf cattail (T. angustifolia) is one of the most common plants in constructed wetlands used for wastewater treatment. Earlier studies have shown that cattails' endophytic bacteria can assimilate nutrients (Whitacre, 2012), heavy metals (Demirezend and Aksoy, 2004) and phytoremediate eutrophic water bodies (Cristina et al., 2009) in the constructed wetland or semi-natural treatment wetland. But no study has investigated the effect of reclaimed water on the rhizosphere bacterial community of T. angustifolia in urbanized riverside wetland. Date from this study can provide better understanding of the interactions between reclaimed water variables and complex bacterial communities in wetland systems, as well as useful information of indigenous populations with potential application to reclaimed water purification. It also can provide a scientific reference to maintain the ecological balance and construct the high-efficiency wetland purification system.

\section{Materials and methods}

\subsection{Description of study area}

The Beijing Yongding River artificial wetland was 5.24-km-long, which geographically begins in the town of Sanjiadian, and extends to Mayu Village, located in Mentougou District. This artificial wetland mainly uses reclaimed water as a supplemental water source to sustain the water inflow in the wetland culverts. The mean water depth in the study area is $1.5-2.5 \mathrm{~m}$. Water storage capacity is $1.6 \times 10^{6} \mathrm{~m}^{3}$. The average annual rainfall of whole watershed is about $556-560 \mathrm{~mm}$, and rainfall mainly concentrates in 6-9 months. To form the wetland landscape, a dam of Sanjiadian reservoir was set up in the upstream of the drainage outlet. Two major reclaimed water outfalls (Zhongmensi ditch outfall and Gaojing canal outfall) are located in approximately $4000 \mathrm{~m}$ downstream of the reservoir 
dam, and amount of annual supplied reclaimed water is about $2 \times 10^{6} \mathrm{~m}^{3}$. Supplementary reclaimed water of wetland was mainly discharged from Mentougou Wastewater Treatment Plant, where the $\mathrm{A}^{2} / \mathrm{O}+\mathrm{MBR}$ (membrane bioreactor) treatment process were adopted to treat urban sewage and partial industrial wastewater surrounding the plant. Aquatic plants in artificial wetland play an important role in reclaimed water purification. The most abundant aquatic plant in artificial wetland is cattails (T. angustifolia), and the vegetation coverage in artificial wetland reaches $70 \%-90 \%$.

\subsection{Sample collection and analysis}

Typha rhizosphere samples were taken from four locations along the artificial wetland (Fig. 1) during October 2012. According to the distribution of Typha in the wetland, the locations were $300 \mathrm{~m}$ upstream of the RWTP outfall (inferred as an undisturbed reference site with respect to the outfall), immediately above and below the outfall, and then downstream at $2000 \mathrm{~m}$ below the outfall. At each location, five replicate Typha rhizosphere soil samples were taken and the sampling points were evenly distributed from the center to both sides of the river, and then evenly blended into one typical sample of Typha rhizosphere. Almost all sampling sites had a depth of $30 \mathrm{~cm}$. The Typha had a height of about $2.5 \mathrm{~m}$. The samples were immediately mixed and transported

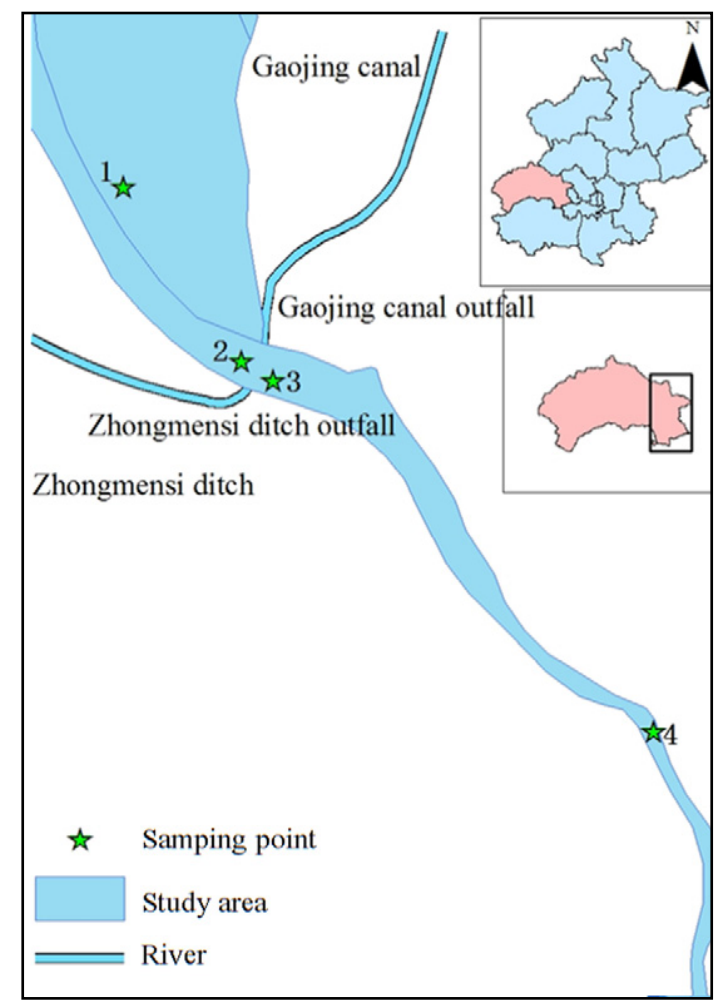

Fig. 1 - Map of artificial wetland in Yongding River, the RWTP, and the sampling locations. Typha rhizosphere samples were taken from four locations along the artificial wetland, location 1 is "undisturbed" with respect to the location of the RWTP outfall, locations 2 and 3 are immediately above and below the outfall, location 4 is $2000 \mathrm{~m}$ downstream of the outfall. to the laboratory. After shaking down loose attachments from the Typha roots, about $0.5 \mathrm{~g}$ of the roots were placed in sterile flasks, and $200 \mathrm{~mL}$ sterile $\mathrm{ddH}_{2} \mathrm{O}$ was added. The samples were stirred for $15 \mathrm{~min}$ in $300 \mathrm{r} / \mathrm{min}$. Subsequently, the plant roots were removed, and then $0.22 \mu \mathrm{m}$ membrane filter was used to remove moisture, and the plant rhizosphere microbial sample was kept on the membrane. Samples on membrane were divided into two parts. One part of sample was used to analyze bacterial community. Another part of sample was carried out conventional physicochemical index analysis. The physicochemical index analytical methods were as follows: determination of total nitrogen (TN) used the Kjeldahl Method (GB/T11894-1989), the total phosphorus (TP) was detected by alkali fusion-Mo-Sb Anti spectrophotometric method (HJ632-2011), the total organic carbon (TOC) was measured by Potassium Dichromate Oxidation Spectrophotometric Method (HJ615/2011), the ammonium nitrogen was measured by $2 \mathrm{~mol} / \mathrm{L} \mathrm{KCl} \mathrm{leaching} \mathrm{indophenol} \mathrm{blue} \mathrm{colorimetric} \mathrm{method,}$ the oxidation-reduction potential of soil sample (ORPs) was measured directly by the oxidation-reduction potential instrument. Furthermore, pH, T (temperature), ORPw (oxidation-reduction potential water sample), Sal (salinity), TDS (total dissolved solid), DO (dissolved oxygen), Chl-a (chlorophyll a) were detected by a water quality meter (Hydrolab Datasonde5, 5×, the United States) through on-site measurement.

\subsection{DNA extraction and PCR amplification}

DNA was extracted from $0.5 \mathrm{~g}$ rhizosphere soil using PowerSoil ${ }^{\mathrm{TM}}$ DNA Isolation Kit 12888-50 (MO BIO, Inc., Solana Beach, CA), following the manufacturer's instructions. The quality and quantity of extracted DNA were verified by agarose gel electrophoresis.

Polymerase chain reaction (PCR) was performed with a pair of primers $27 f$ (5'- (6-FAM)-AGAGTTTGATCCTGGCTCAG-3') and 1492r (5'-GGTTACCTTGTTACGACTT-3') (Shanghai Sangon Biotech Co. Ltd., China) to amplify the 16S rRNA of the cattails rhizosphere bacteria. The $25 \mu \mathrm{L}$ PCR mixture contained $2 \mu \mathrm{L}$ of genomic DNA, $12.5 \mu \mathrm{L} 2 \times$ Taq reaction buffer, $1 \mu \mathrm{L}$ of primer $27 \mathrm{f}$ $(10 \mu \mathrm{mol} / \mathrm{L})$ and $1 \mu \mathrm{L}$ of primer $1492 \mathrm{r}(10 \mu \mathrm{mol} / \mathrm{L})$ and $8.5 \mu \mathrm{L}$ $\mathrm{ddH}_{2} \mathrm{O}$. PCR cycling parameters consisted of an initial denaturation step at $95^{\circ} \mathrm{C}$ for $5 \mathrm{~min}$, followed by 30 amplification cycles of $95^{\circ} \mathrm{C}$ for $50 \mathrm{sec}, 55^{\circ} \mathrm{C}$ for $50 \mathrm{sec}, 72^{\circ} \mathrm{C}$ for $1 \mathrm{~min}$ and a final elongation at $72^{\circ} \mathrm{C}$ for $7 \mathrm{~min}$. After fluorescent PCR amplification products were identified using $0.8 \%(\mathrm{~m} / \mathrm{V})$ agarose gel electrophoresis, then wrapped with tinfoil and stored at $4^{\circ} \mathrm{C}$.

\subsection{T-RFLP analysis and phylogenetic assignment}

All T-RFLP analyses were carried out as previously described (Dunbar et al., 2001; Blackwood et al., 2003; LaMontagne et al., 2003). Briefly, all fluorescently labeled PCR amplification products were digested with MspI, HhaI and RsaI enzymes (Takara Co., Japan) at $37^{\circ} \mathrm{C}$ for $4 \mathrm{hr}$. Each $10 \mu \mathrm{L}$ digestion reaction contained $5 \mu \mathrm{L}$ of PCR products, $1 \mu \mathrm{L} 10 \times$ Taq reaction buffer, $\mathrm{ddH}_{2} \mathrm{O} 3.5 \mu \mathrm{L}$ added, $0.5 \mu \mathrm{L}$ of $\mathrm{MspI}$, HhaI and RsaI enzymes in separate reactions at $37^{\circ} \mathrm{C}$ for $4 \mathrm{hr}$. And then incubate for $15 \mathrm{~min}$ under the condition at $65^{\circ} \mathrm{C}$ to make enzyme inactivation. After that, Genomic Scanning of 
enzyme-digested products was carried out by Tiangen Biotech (Beijing) Co., Ltd., China to obtain T-RFLP profiles. Fragments larger than 500 or smaller than $50 \mathrm{bp}$ were deleted from analysis. Relative abundance of each terminal restriction fragments (T-RFs) was calculated and the T-RFs with relative area percents less than $1 \%$ were also deleted from further analysis.

The web-based, T-RFLP Phylogenetic Assignment Tool (PAT), was used for designation of names to T-RFs. The reference database used was the default database for PAT, generated using the Microbial Community Analysis query function found at the MiCA website (http://mica.ibest.uidaho. edu/). Only phylogenetic assignments that have matched $\mathrm{T}$-RF lengths in all two restriction enzymes were used, and the rest was discarded.

The cluster analysis was performed based on the T-RFLP profiles using the PRIMER 5 software. Shannon diversity index $\left(\mathrm{H}^{\prime}\right)$ was determined using Eq. (1):

$H^{\prime}=-\sum\left(p_{\mathrm{i}}\right)\left(\ln p_{\mathrm{i}}\right)$

while evenness ( $\left.J^{\prime}\right)$ was calculated as Eq. (2):

$J^{\prime}=H^{\prime} / \ln S$

and Simpson's diversity index (1/D) as Eq. (3):

$(1 / D)=1 / \Sigma p_{i}^{2}$

where, $p_{\mathrm{i}}$ is the relative abundance of T-RFs, $S$ is the number of $\mathrm{T}$-RFs, and $\mathrm{D}$ is for Simpson's dominance index, which is inversely proportional to diversity.

\subsection{S rRNA gene clone library and phylogenetic analysis}

Bacterial 16S rRNA gene clone libraries were constructed from the Typha rhizosphere samples of upstream and downstream of the RWTP outfall. The PCR condition and primers were the same as those used for bacterial T-RFLP analysis, except that the forward primer was not labeled with 6-FAM. Concentration detection of the purified PCR amplification products was done by the Biophotometer in conjugation experiments. The purified PCR products were ligated into the pGEM-T Easy vector (Promega Co., the United States). Subsequently, Escherichia coli Trans1-T1 competent cells (TransGen Biotech Co., China) were transformed with the ligation products and spread onto LB agar plates with ampicillin (100 mg/L), X-gal and IPTG for standard blue and white screening (Sambrook and Russell, 2001). Randomly selected colonies were checked directly by PCR amplification with primers SP6 (ATTTAGGTGACACTATAGAA) and T7 (TAATACGACTCACTATAGGG) for the vector (Takara Co., Japan). And a total of 420 positive clones from the upstream library and 320 positive clones from the downstream library were sequenced using an ABI PRISM 3730 automatic sequencer (Shanghai Sangon Co. Ltd., China).

The obtained sequence data were tested by the ChimeraCheck program (www.cardiff.ac.uk/biosi/research/biosoft) to remove artificial chimerical sequences. The remaining sequences within each library were grouped into operational taxonomic units (OTUs) based on 97\% sequence similarity using the furthest-neighbor algorithm in Mothur software
(Schloss et al., 2009). The get.oturep command in Mothur was used to select representative sequences and they were used for all subsequent analyses (Schloss et al., 2009; Sullam et al., 2012). The taxonomic affiliation of each representative sequence was compared with the NCBI database using BLASTN or aligned by the identify analysis of EzTaxon server 2.1. Sequences with $>97 \%$ similarity were assigned to the same species. The selected strains all had the highest sequence homology and were qualified published. MEGA 5 software was used for analysis. Then, Clustal W software was used to sort the samples according to maximum homology.

\subsection{Coverage of clone libraries}

To estimate the representation of the library, coverage of clone library $(C, \%)$ was calculated by the following equation based on the sequencing results:

$C=(1-n / N) \times 100 \%$

where, $n$ is the number of single clones, and $N$ is the total number of clones in the clone library.

\section{Results}

2.1. Water quality and soil physicochemical properties in T. angustifolia rhizosphere sampling site

The detection results of water quality characteristics and physicochemical properties of T. angustifolia rhizosphere soil in sampling sites are shown in Table 1. For these detected physicochemical properties of the water and sediment, ANOVA (analysis of variance) and Tukey's HSD were performed to assess differences between different spatial points. ORPs, $\mathrm{NH}_{4}^{+}-\mathrm{N}, \mathrm{pH}, \mathrm{ORPw}$, Sal, TDS, DO and Chl-a were screened out by one-way ANOVA $(p<0.05)$, which means that those indicators were significantly affected by reclaimed water supplement and wetland purification. As shown in Table 1, the water quality indicators Sal, TDS and Chl-a were markedly higher in the pool below outfall than in the pool above outfall because of the reclaimed water supplement. ORPs increased slightly in the pool below outfall with DO decrease dramatically, maybe due to the disturbance of rhizosphere soil caused by reclaimed water supplement, while the significant reduction happened in the downstream. Besides that, the $\mathrm{NH}_{4}^{+}-\mathrm{N}$ was also significantly increased in the near outfall, while it was significantly decreased in $2000 \mathrm{~m}$ below outfall. Obviously, the wetlands play an important role in removing $\mathrm{NH}_{4}^{+} \mathrm{N}$, and the removal efficiency was $45.83 \%$ by concentration depletion. Compared to the other sampling sites, the sediment physicochemical indicators TN, TP, TOC were slightly higher in the upstream, this may have been due to the reduction in flow resulted in the deposition of organic matter and other material.

\subsection{Diversity of rhizosphere bacterial community as determined by T-RFLP}

Community diversities were estimated by number of ribotypes, evenness index, Shannon and Simpson's diversity index based on the T-RFLP profiles (Table 2). The chart in Table 2 shows that 


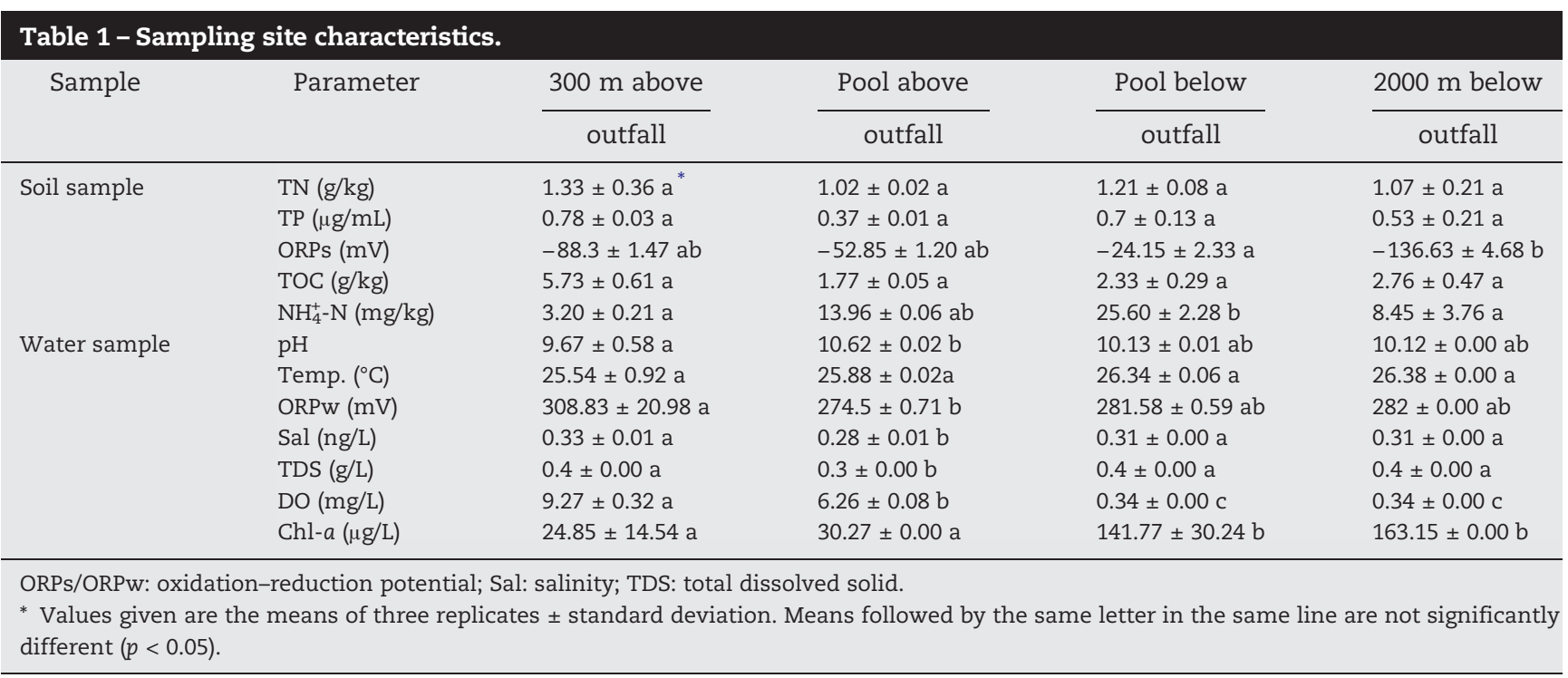

RWTP effluent strikingly changed the rhizosphere bacterial communities structure characteristics, which led to bacterial community richness index, diversity index and evenness index decrease dramatically in the near outfall. However, they were markedly increased in the $2000 \mathrm{~m}$ below outfall relative to the near outfall. Briefly, the result shows that a decrease in bacterial richness, evenness and diversity with an increase of the reclaimed water interference intensity. According to the above analyzed result, we found that community diversities generated by the MspI and HhaI enzymes digestion were slightly higher than that by the RsaI enzyme. So, the following cluster analysis was performed based on the result of the MspI and HhaI enzymes digestion. The cluster analysis results generated by the two restriction enzymes were extremely consistent (Fig. 2). There were significant differences in the bacterial community structure according to location. Results of the clustering analysis showed that two samples derived from the near outfall have a low degree of similarity. However, the similarity was higher relatively between the $2000 \mathrm{~m}$ below outfall sampling site and the $300 \mathrm{~m}$ above outfall sampling site, which means that the diversity of rhizosphere bacterial communities was markedly changed at the near outfall locations because of reclaimed water supplement and then restored gradually in the downstream.

\subsection{Comparison of taxonomic composition of upstream and} downstream rhizosphere soil samples based on T-RFLP profile

From the phylum diversity result, it was found that RWTP effluent did have a marked impact on the bacterial community diversity (Fig. 3). Overall, the bacterial communities in the upstream point contained 15 bacterial phyla. The predominant phyla belonged to $\gamma$-Proteobacteria, Actinobacteria, $\beta$-Proteobacteria and Bacteroidetes, with the remainder spread among Firmicutes, $\varepsilon$-Proteobacteria, Fusobacteria, and other minor groups. While the phylum number of bacterial community in the downstream point was 11, which decreased $60 \%$ than that of upstream point. In detail, the diversity of $\gamma$-Proteobacteria, $\beta$-Proteobacteria, $\varepsilon$-Proteobacteria, Actinobacteria, Bacterodetes, Firmicutes and Fusobacteria was decreased. However, the diversity of Planctomycetes, $\alpha$-Proteobacteria, and $\delta$-Proteobacteria was increased in the downstream. It is noteworthy that the bacterial community diversity was low extremely near the outfall, and only three matched bacteria were obtained from the database, including Delftia sp., Flavobacterium sp. and Thermotoga sp.

\subsection{Comparison of taxonomic composition of upstream and downstream rhizosphere soil samples based on 16S rRNA gene clone library analysis}

In order to further understand the differences of rhizosphere bacterial function and community structure between the upstream and downstream locations, T. angustifolia rhizosphere bacterial communities derived from the upstream and downstream were explored using a 16S rRNA library. A total of 420 positive clones were obtained from the upstream library. Among them, 28 bad sequences were deleted and the

Table 2-Richness (number of ribotypes), evenness, Shannon diversity and Simpson's diversity indices of bacterial community in rhizosphere soil from different sampling sites based on T-RFLP analysis.

\begin{tabular}{|c|c|c|c|c|c|c|c|c|c|c|c|c|}
\hline \multirow{2}{*}{$\begin{array}{l}\text { Sampling } \\
\text { site }\end{array}$} & \multicolumn{3}{|c|}{ Number of ribotypes } & \multicolumn{3}{|c|}{ Evenness index } & \multicolumn{3}{|c|}{ Shannon diversity } & \multicolumn{3}{|c|}{ Simpson's diversity } \\
\hline & MspI & HhaI & RsaI & MspI & HhaI & RsaI & MspI & HhaI & RsaI & MspI & HhaI & RsaI \\
\hline $300 \mathrm{~m}$ above outfall & 61 & 31.5 & 8.5 & 0.9 & 0.92 & 0.75 & 3.69 & 3.17 & 1.61 & 0.98 & 0.96 & 0.72 \\
\hline Pool above outfall & 16 & 21 & 10 & 0.61 & 0.55 & 0.62 & 1.68 & 1.68 & 1.44 & 0.7 & 0.69 & 0.68 \\
\hline Pool below outfall & 4 & 10.5 & 1.5 & 0.79 & 0.74 & 0.25 & 1.07 & 1.74 & 0.18 & 0.59 & 0.72 & 0.1 \\
\hline $2000 \mathrm{~m}$ below outfall & 22.67 & 40.67 & 8 & 0.84 & 0.86 & 0.51 & 2.6 & 3.16 & 0.91 & 0.88 & 0.94 & 0.48 \\
\hline
\end{tabular}




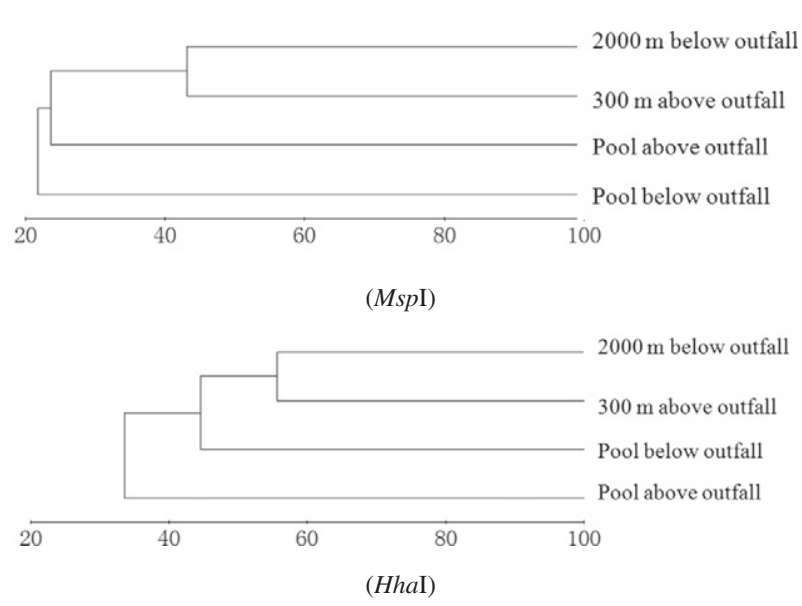

Fig. 2 - Dendrogram of hierarchical cluster analysis based on the T-RFLP profiles of $T$. angustifolia rhizosphere soil samples digested with two restriction (MspI, HhaI) enzymes.

remaining 392 were positive clones. The remaining sequences were grouped into 48 different OTUs with $>97 \%$ sequence identity by Muther soft. These sequence data have been submitted to the GenBank databases under the accession number KR095234-KR095278. Additionally, the calculated coverage of the clone library was $97.95 \%$. For the downstream library, two hundred and seventy-five individual sequences derived from 320 positive clones were verified by colony PCR and submitted to GenBank (accession no.: KR095199KR095233), and the calculated coverage of the clone library was $97.82 \%$.

Phylogenetic analysis of all the sequences in the upstream sample revealed that the majority of clones were affiliated with Proteobacteria (259 clones, 66.04\%) and Bacteroidetes (57 clones, $14.55 \%)$. The other clones belonged to Acidobacteria (14 clones, $3.85 \%$ ), Verrucomicrobia (12 clones, 3.06\%), Gemmatimonadetes (11 clones, 2.81\%), Firmicutes (4 clones, 1.03\%) and uncultured bacterium (35 clones, 8.93\%). Analysis based on the class level showed that the most abundant taxa of Proteobacteria were $\beta$-Proteobacteria (118 clones, 30.14\%) and $\varepsilon$-Proteobacteria (65 clones, $16.58 \%$ ), followed by $\delta$-Proteobacteria (40 clones, $10.12 \%$ ), $\alpha$-Proteobacteria (20 clones, 5.11\%) and $\gamma$-Proteobacteria (16 clones, $4.09 \%$ ) in the Proteobacteria phyla. In the downstream sample the most abundant phyla was also Proteobacteria (137 clones, $49.82 \%$ ), followed by Bacteroidetes (45 clones, $16.36 \%$ ). The other clones belonged to Firmicutes (24 clones, $8.73 \%$ ), Chloroflexi (21 clones, 7.64\%), Acidobacteria (16 clones, 5.82\%), Verrucomicrobia (8 clones, $2.91 \%$ ) and Gemmatimonadetes (4 clones, $1.45 \%)$. In the Proteobacteria phyla, the most abundant taxa of Proteobacteria were $\beta$-Proteobacteria (50 clones) and $\gamma$-Proteobacteria (45 clones), the proportion of which was $18.18 \%$ and $16.36 \%$ respectively, followed by $\delta$-Proteobacteria (27 clones, 9.82\%), $\alpha$-Proteobacteria (10 clones, 3.64\%) and $\varepsilon$-Proteobacteria (5 clones, $1.82 \%$ ). Details of all OTUs in the two clone libraries are listed in Tables S1 and S2. Overall, there were some differences among upstream and downstream samples in the distribution of the taxonomic groups. As shown in the Fig. 4, RWTP effluent markedly reduced the relative abundance of Proteobacterial sequences, and the decrease of which was driven mainly by a decrease in the abundance of $\beta$-Proteobacteria and $\varepsilon$-Proteobacteria, while an increase in the relative abundance of $\gamma$-Proteobacteria at the downstream samples. Additionally, there was a striking increase in the relative abundance of Firmicutes and Chloroflexi sequences.

$\beta$-Proteobacteria was the most abundant class in the phylum of Proteobacteria from the upstream and downstream sediments, while the relative abundance of $\beta$-Proteobacteria was markedly higher in the upstream without reclaimed water influence. In the upstream, 118 clones in the class $\beta$-Proteobacteria comprising 18 OTUs were mainly related to five orders of bacteria, which included Burkholderiales, Rhodocyclales, Hydrogenophilales, Methylophilales and Nitrosomonadales, the remainder belong to unclassified. However, there are only four OTUs, which comprised 50 clones, were found in the downstream sample. In detail, Burkholderiales was the most abundant order in the class of $\beta$-Proteobacteria in the upstream and downstream samples, and the clones in the two clone libraries exhibited the higher levels of similarity to Burkholderiales. The members of Rhodocyclales were highly enriched in the upstream sample,

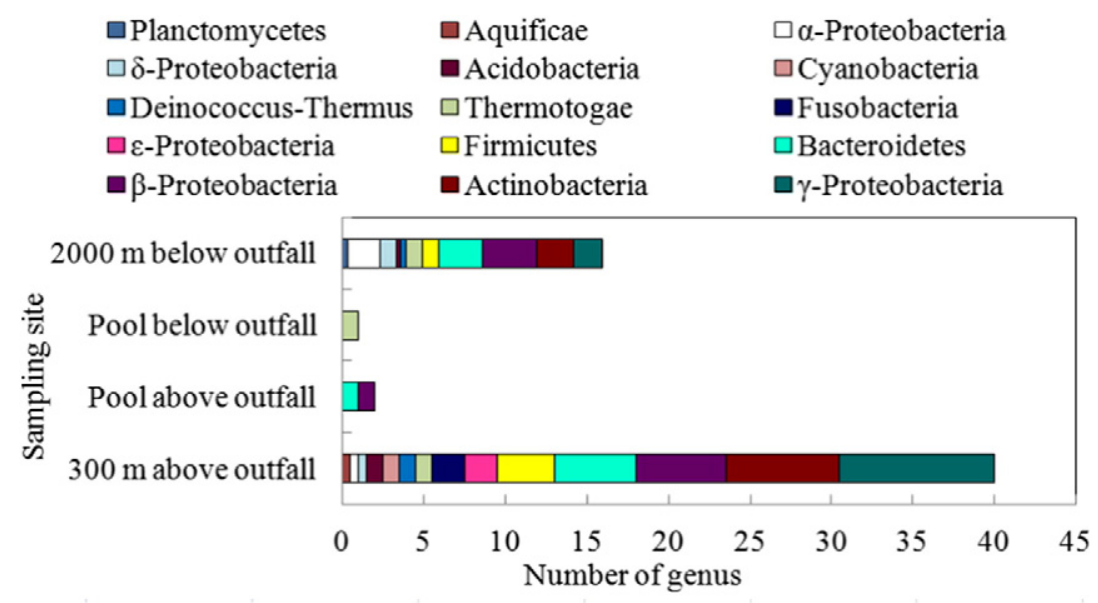

Fig. 3 - Barchart of bacterial community diversity in Typha rhizosphere classification based on phylum level. 


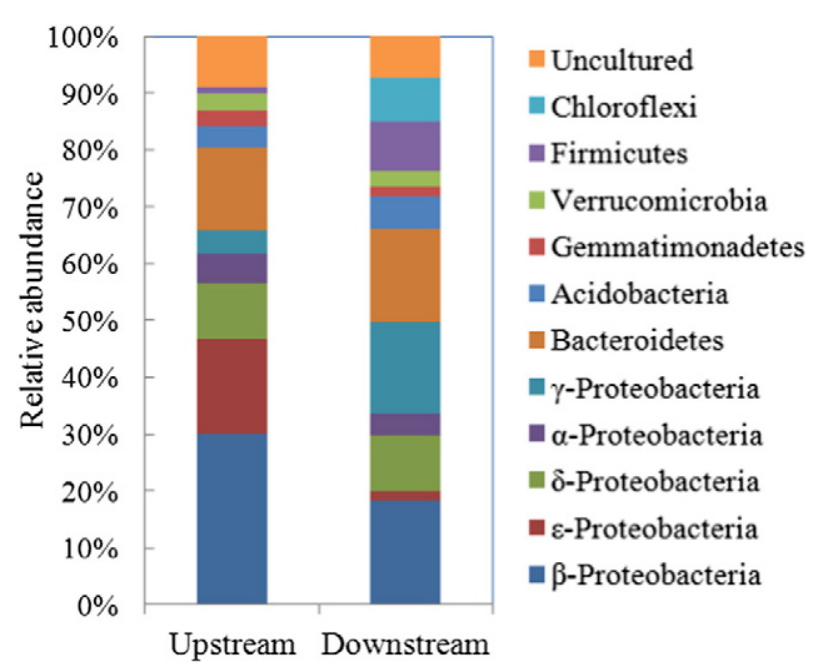

Fig. 4 - Phylogenetic distribution of the OTUs in the two clone libraries. Relative read abundance of different bacterial phyla within the different communities. Sequences that could not be classified into any known group were assigned as 'Uncultured'.

but were not detected in the downstream. Some studies have shown that Rhodocyclales played an important role in organic pollutant and nitrogen compound removal (Xia et al., 2012). The relative abundance of Hydrogenophilales was markedly increased in the downstream sample. In the upstream, 12 clones comprising two OTUs associated with heavy metal resistance from polluted sediment had high similarity with Thiobacillus sp., each OTU was respectively isolated from $\mathrm{Hg}$ polluted sediment and leachate sediment (Regier et al., 2012; Liu et al., 2011). In the downstream, one OTU of a total of 18 clones were highly similar to Hydrogenophilaceae from the anaerobic environment in tar oil contaminant plume (Winderl et al., 2008).

$\varepsilon$-Proteobacteria was the secondary abundant class in the phylum of Proteobacteria in the upstream, and the obvious decrease of $\varepsilon$-Proteobacteria abundant happened in the downstream. The most abundant genus was Sulfuricurvum sp. RIFRC-1 in the study area. A few studies have been reported, bacteria belonging to the genus of Sulfuricurvum in the family of Helicobacteraceae are usually a facultatively anaerobic, chemolithoautotrophic, sulfur-oxidizing bacterium (Kodama and Watanabe, 2004).

The relative abundance of $\gamma$-Proteobacteria was markedly increased in the downstream, especially Sinobacteraceae and Xanthomonadaceae. In the downstream, forty-two clones in the class $\gamma$-Proteobacteria comprising three OTUs were related to two families (Sinobacteraceae and Xanthomonadaceae) and these included three genera (Steroidobacter, Xanthomonas and Lysobacter). A majority of the sequences (26 clones) exhibited high similarity to bacteria of genus Steroidobacter sp., which was the most abundant genus in the class of $\gamma$-Proteobacteria in the downstream sample and originally isolated from $\mathrm{Hg}$ polluted sediment (Regier et al., 2012). Sixteen clones were closely related to Xanthomonadaceae and belonged to genera Xanthomonas and Lysobacter. It has been reported that Xanthomonas sp. is an active participant in the degradation of contaminants, such as petrochemical compounds (HernandezRaquet et al., 2006; Lafortune et al., 2009). Additionally, a few studies have been reported that the microorganisms belonging to the order Xanthomonadales are linked normally to plants diseases (Bashan, 1986; Alfano and Collmer, 1996).

Among non-Proteobacteria, a higher relative abundance of Firmicutes and Chloroflexi sequences was detected at the downstream site. In Firmicutes, 24 clones grouped into Clostridium sp. in the downstream, including three OTUs, were closely related to three different species of Clostridium. Each OTU was respectively originally isolated from leachate sediment, a contaminated aquifer and hexavalent chromium contaminated soil. In Chloroflexi, a total of 15 clones comprise three OTUs in the family of Anaerolineaceae. Among them, the most dominant OTU, which comprised 11 clones, was very similar to Anaerolineaceae, which is originally isolated from Ajka red mud contaminated soils with arsenic, chromium, molybdenum and Vanadium during progressive anoxia. The other 10 clones were related to the genera Longilinea and Anaerolineas.

\section{Discussion}

Concerning the bacterial community in the tissue of T. angustifolia in the wetland with RWTP effluent supplement, so far, a few studies have been performed. Li et al. (2011) and Guo et al. (2015) examined the endophytic bacterial diversity in the root of $\mathrm{T}$. angustifolia by using 16S rRNA clone library analysis. Both their results showed that Proteobacteria were found to be the predominant phylum and $\beta$-Protebacteria were the most abundant class in the phylum of Proteobacteria, followed by $\gamma$-Proteobacteria, $\delta$-Proteobacteria, $\alpha$-Proteobacteria and $\varepsilon$-Proteobacteria, which were in agreement with the study in the downstream sample. Although those studies were performed in the wetland with RWTP effluent supplement, they didn't compare with other sample for this kind of special water quality. This paper takes the upstream sample as a comparison, trying to evaluate the impact of RWTP effluent on bacterial function and community structure in the T. angustifolia rhizosphere sample.

Using a combination of terminal restriction fragment length polymorphism (T-RFLP) and clone library analyses of the 16S rRNA gene sequences, we evaluated the impact of RWTP effluent on the ecology of bacterial communities in the T. angustifolia rhizosphere sample. The result of community diversity analysis showed that bacterial richness, evenness and diversity decreased dramatically with the increase of the reclaimed water interference intensity. Differences in bacterial community characteristics were strongly linked with the water quality characteristics and physicochemical properties of the sediment. However, the detected eutrophication indicators (TN, TP, ORP, TOC, $\mathrm{NH}_{4}^{+}-\mathrm{N}, \mathrm{pH}, \mathrm{Sal}, \mathrm{TDS}, \mathrm{DO}$ and Chl-a) did not show the corresponding variation. For example, when comparing the above indicators in the pool below outfall with that in the downstream, we would find that they were either nearly the same values or decrease. However, the bacterial community diversity was markedly increased in the downstream. Additionally, in contrast to the upstream, the richness, evenness and diversity of bacterial community in 
the pool below was extremely low, indicating that there may have been a secondary effect from the RWTP effluent affecting the bacterial community characteristic near the outfall. It is well known that RWTPs are a significant source of disinfection byproducts, antibiotics, heavy metals, pharmaceuticals and pesticides, which may produce detrimental effects on microbial communities (Drury et al., 2013; Proia et al., 2013). Based on these observations, we expected that microbial diversity may be affected by some toxic compounds containing RWTP effluent, which might have contributed to a decrease in bacterial diversity from near the outfall sites, while the recovery of wetland ecosystem by the wetland plant rhizosphere microorganism associated with plants contributed to the rise in bacterial diversity and species richness at the downstream location (Stottmeister et al., 2003). This result was accordant with published study on the shifts in sediment bacterial communities caused by RWTP effluent (Ma et al., 2014).

Rhizophere bacterial community is the main force involved in the degradation of pollutants and playing an important role in maintaining the balance of wetland ecosystem and achieving ecological purification (Feng et al., 2012), while the bacterial biomass, bacterial diversity, bacterial community structure and composition may also be affected by pollutants containing RWTP effluent. A higher relative abundance of $\gamma$-Proteobacteria, Firmicutes and Chloroflexi and a lower proportion of $\beta$-Proteobacteria and $\varepsilon$-Proteobacteria sequences was detected at the downstream site compared to the upstream site. The higher proportion of Firmicutes and Chloroflexi sequences reflects the impact of RWTP effluent, because some members of these phyla have been proposed as indicators of fecal pollution, and they were commonly abundant in anaerobic wastewater treatment systems (Riviere et al., 2009). Previous studies have also demonstrated that the class Clostridia, which was dominant among the Firmicutes at the downstream point, has frequently been detected within urban wastewater systems (Vierheilig et al., 2013).

In this study, a total of $21.7 \%$ of the clones in the upstream clone library may be closely related to the biological cycle of nitrogen (nitrogen fixation, ammonification, nitrification and denitrification) in wetland systems. The majority of the sequences belonged to Sulfuricurvum sp. RIFRC-1, Burkholderia sp. S1-40 and Rhodocyclus sp. W4S68, with the remainder spread among Rhodocyclaceae, Comamonadaceae, and other minor groups. Among them, Sulfuricurvum sp. RIFRC-1 could translate nitrate into nitrite (Kodama and Watanabe, 2004), Burkholderia sp. S1-40 had a strong denitrogenation ability (Yoshida et al., 2012) and Rhodocyclus sp. W4S68 was capable of reducing nitrate (Hougardy and Klemme, 1995). What's more, a total of $19.27 \%$ of the clones in the downstream clone library may be closely related to the biological cycle of nitrogen, such as Burkholderia sp. S2-86, Steroidobacter sp. (Fahrbach et al., 2008), Geobacter sp. KB-11 (Lovley et al., 1993), Phenylobacterium sp. b2-194 (Lingens et al., 1985) and Sulfuricurvum sp. RIFRC-1. For the biological cycle of phosphorus, a total of $6.13 \%$ clones in the upstream clone library may be closely related to the biological cycle of phosphorus in wetland systems, mainly including Rhodocyclus sp. W4S68 (Ahn et al., 2001), Dechloromonas sp. 4y-107 (Zhang et al., 2011) and Gemmatimonas sp. Wbfc97 (Yang et al., 2012). In contrast to the upstream, about $6.9 \%$ clones were related to the biological cycle of phosphorus in the downstream, belonging to Bacteroidetes and Gemmatimonadetes. In the upstream clone library, about $25.04 \%$ of the bacterial community groups showed a close relationship with carbon recycling, such as Ramlibacter sp. W1.09-2 (Heulin et al., 2003), Rhodocyclus sp. W4S68 (Pfennig, 1978), Methylobacillus sp. R15-12 (Akinori et al., 2002), Tolumonas sp. R40-25 (Fischer-Romero et al., 1996), Prolixibacter sp. (Holmes et al., 2007) and Geothrix sp. MOBA74_25m (Coates et al., 1999). Approximately $26.55 \%$ of the bacterial community groups were closely related to carbon recycling in the downstream clone library. The most dominant genera were Clostridium spp. (Zhao et al., 2008), Desulfobacula sp. LU2-210 and Phenylobacterium sp. b2-194, followed by Lysobacter sp. T313C8, Geobacter sp. KB-11 and Alkaliflexus sp. Pad-81. A total of $19.65 \%$ clones in the upstream clone library may be closely related to the biological cycling of sulfur in wetland systems. Some principle members of the genera Sulfuricurvum sp., Desulfomicrobium sp. (Azabou et al., 2007), Desulfuromonas sp. (Pfennig, 1978) and Thiobacillus sp. (Visser et al., 1997) all played an important role in the sulfur cycle in wetland. A total of $20.37 \%$ of the clones in the downstream clone library may be closely related to the biological cycling of sulfur in wetland systems, main including Clostridium spp. (Zhao et al., 2008), Desulfomicrobium sp., Desulfobacula sp. LU2-210 and Geobacter sp. KB-11 in $\delta$-Proteobacteria and Sulfuricurvum sp. RIFRC-1 in $\varepsilon$-Proteobacteria.

Based on the above analysis, we could conclude that the bacterial community function structure characteristics didn't strikingly change for nitrogen cycle, phosphorus cycle and carbon cycle between the upstream and downstream. This is the reason that the nutrient indicators TN, TP and TOC did not change significantly between the upstream and downstream. Based on the above conclusion, it is further confirmed that there may have been a secondary effect from the RWTP effluent affecting the bacterial community characteristic, such as heavy metals.

A large number of studies have shown that reclaimed water contains residue of halogenated hydrocarbons, heavy metal, antibiotics and other drugs contaminate groundwater when it replenishes river channels, which may produce detrimental effects on microbial communities (Drury et al., 2013). In the case of those pollutants, substantial changes happened in bacterial structure and composition. This study showed that about $9.45 \%$ clones were closely associated with the resistance of antibiotics containing environments in the upstream sediment, with dominant groups of Comamonas sp. R15-4, Rhodocyclus sp. W4S68 and Methylobacillus sp. R15-12 in $\beta$-Proteobacteria and Tolumonas sp. R40-25 in $\gamma$-Proteobacteria. Approximately $7.64 \%$ clones in the downstream clone library may be closely related to the resistance of antibiotics in wetland systems, which belong to Burkholderiales bacteria. For the bacterial community related to the resistance of halogenated hydrocarbons in wetland systems, a total of $3.33 \%$ of the clones in the downstream clone library may be closely associated with the resistance of halogenated hydrocarbons in wetland systems and 3.6\% clones in the downstream clone library. It is noteworthy that a total of $6.13 \%$ of the clones in the upstream clone library might be specifically associated with heavy metal containing environments. While $14.9 \%$ clones in the downstream clone library may be closely related to the heavy metal in wetland systems, some 
heavy-metal resistant bacteria Steroidobacer sp., Geobacter sp. KB-11 and Clostridium sp. XT40, which were found at the downstream site, were not detected or only rarely detected at the upstream site. Obviously, the relative abundance of heavy-metal resistant bacteria striking changed between the upstream and the downstream, and the downstream sample corresponded to higher abundance of these bacteria. Combined with the analysis results of physicochemical properties of $T$. angustifolia rhizosphere soil, we would expect that bacterial diversity may be affected by the heavy metal.

It is well known that RWTP effluent is rich in pathogenic bacteria, which may produce detrimental effects on humans (Toze, 2006). Compared to the upstream, the pathogenic bacteria were markedly increased in the downstream rhizosphere soil. Approximately $12.37 \%$ clones of pathogenic were detected in the downstream clone library, with dominant groups of Clostridium sp. (Butel et al., 1998) and Xanthomonas sp. burs_22 (Li et al., 2008). However, few potentially pathogenic bacteria were detected in the upstream. On the other hand, Plant growth-promoting rhizobacteria (PGPR) were markedly decreased in the downstream sediment since reclaimed water supplement. About 27 clones of PGPR were obtained from the upstream clone library, including Burkholderia sp. (Estrada-De Los Santos et al., 2001) and Rhizobium sp. While a total of 7 PGPR clones were detected in the downstream, which belong to Burkholderia sp.

\section{Conclusions}

The combination of T-RFLP and 16S rRNA gene library techniques was a powerful approach for understanding the diversity and community structure of T. angustifolia rhizosphere bacteria in the constructed Beijing Mayu Wetland. In our survey, RWTP effluent could markedly change the rhizosphere bacterial community structure characteristics, resulting in decrease in bacterial community richness, evenness and diversity from downstream site. Rhizosphere bacterial community function may be changed between the upstream and downstream locations, simultaneously. These changes may be caused by heavy metals and other drugs contaminate containing RWTP effluent. The relative abundance of bacteria closely related to the resistant of heavy-metal was markedly changed, while the bacterial community function structure characteristics didn't change significantly for nitrogen cycle, phosphorus cycle, carbon cycle and sulfur cycle between the upstream and downstream sites. Additionally, the pathogenic bacteria were markedly increased in the downstream rhizosphere sample because of RWTP effluent supplement, while PGPRs were markedly decreased in the downstream sample. Though, of course, all these conclusions will be further confirmed with corresponding data based on analyses for bacterial resistance to heavy-metals, the presence of PGPR features, detection of respective functional genes in the metagenomic DNA, water quality, soil physicochemical properties, etc.

\section{Acknowledgments}

This work was supported by the National Natural Science Foundation of China (No. 40901281), the Beijing of Education
Science and Technology Program (No. KM201310028012), and the International S\&T Cooperation Program of China (No. 2014DFA21620).

\section{Appendix A. Supplementary data}

Supplementary data to this article can be found online at http://dx.doi.org/10.1016/j.jes.2016.06.022.

\section{R E F E R E N C E S}

Ahn, J., Daidou, T., Tsuneda, S., Hirata, A., 2001. Selection and dominance mechanisms of denitrifying phosphate-accumulating organisms in biological phosphate removal process. Biotechnol. Lett. 23 (24), 2005-2008.

Akinori, Y., Miho, A.G., Kinya, F., Hiroyuki, U., Takayuki, U., Kazuo, A., 2002. Production of aldehyde oxidases by microorganisms and their enzymatic properties. J. Biosci. Bioeng. 94 (2), 124-129.

Alfano, J.R., Collmer, A., 1996. Bacterial pathogens in plants: life up against the wall. Plant Cell 8 (10), 1683-1698.

Azabou, S., Mechichi, T., Patel, B.K., Sayadi, S., 2007. Isolation and characterization of a mesophilic heavy-metals-tolerant sulfate-reducing bacterium Desulfomicrobium sp. from an enrichment culture using phosphogypsum as a sulfate source. J. Hazard. Mater. 140 (1), 264-270.

Bashan, Y., 1986. Field dispersal of Pseudomonas syringae pv. tomato, Xanthomonas campestris pv. vesicatoria, and Alternaria macrospora by animals, people, birds, insects, mites, agricultural tools, aircraft, soil particles, and water sources. Can. J. Bot. 64 (2), 276-281.

Blackwood, C.B., Marsh, T., Kim, S.H., Paul, E.A., 2003. Terminal restriction fragment length polymorphism data analysis for quantitative comparison of microbial communities. Appl. Environ. Microbiol. 69 (2), 926-932.

Butel, M.J., Roland, N., Hibert, A., Popot, F., Favre, A., Tessedre, A.C., et al., 1998. Clostridial pathogenicity in experimental necrotising enterocolitis in gnotobiotic quails and protective role of bifidobacteria. J. Med. Microbiol. 47 (5), 391-399.

Coates, J.D., Ellis, D.J., Gaw, C.V., Lovley, D.R., 1999. Geothrix fermentans gen. nov., sp. nov., a novel Fe (III)-reducing bacterium from a hydrocarbon-contaminated aquifer. Int. J. Syst. Evol. Microbiol. 49 (4), 1615-1622.

Cristina, S.C.C., Duquea, A.F., Alexandra, M., Isabel, S.H., António, C., António, O.S.S.R., et al., 2009. Substrate effect on bacterial communities from constructed wetlands planted with Typha latifolia treating industrial wastewater. Bioresour. Technol. 100 (13), 3228-3235.

Cui, F., Sirotin, M.V., Zhurkin, V.B., 2011. Impact of Alu repeats on the evolution of human p53 binding sites. Biol. Direct 6 (2), 6150-6169.

Demirezend, D., Aksoy, A., 2004. Accumulation of heavy metals in Typha angustifolia (L.) and Potamogeton pectinatus (L.) living in Sultan Marsh (Kayseri, Turkey). Chemosphere 56 (7), 685-696.

Dong, L., Tao, Y., Zhang, Y., 2010. Antibiotic resistance characteristics of environmental bacterial from an ox tetracycline production wastewater treatment plant and the receiving river. Appl. Environ. Microbiol. 76 (11), 3444-3451.

Drury, B., Rosi-Marshall, E., Kelly, J.J., 2013. Wastewater treatment effluent reduces the abundance and diversity of benthic bacterial communities in urban and suburban rivers. Appl. Environ. Microbiol. 79 (6), 1897-1905

Dunbar, J., Ticknor, L.O., Kuske, C.R., 2001. Phylogenetic specificity and reproducibility and new method for analysis of terminal restriction fragment profiles of 16S rRNA genes from bacterial communities. Appl. Environ. Microbiol. 67 (1), 190-197. 
Estrada-De Los Santos, P., Bustillos-Cristales, R., Caballero-Mellado, J., 2001. Burkholderia, a genus rich in plant-associated nitrogen fixers with wide environmental and geographic distribution. Appl. Environ. Microbiol. 67 (6), 2790-2798.

Fahrbach, M., Kuever, J., Remesch, M., Huber, B.E., Kämpfer, P., Dott, W., et al., 2008. Steroidobacter denitrificans gen. nov., sp. nov., a steroidal hormone-degrading gammaproteobacterium. Int. J. Syst. Evol. Microbiol. 58 (9), 2215-2223.

Feng, C.L., Li, K.L., Li, Y., 2012. Characteristics of microbial community in constructed wetlands and their purification mechanism. J. Cent. South Univ. 32 (12), 42-45.

Fischer-Romero, C., Tindall, B.J., Jüttner, F., 1996. Tolumonas auensis gen. nov., sp. nov., a toluene-producing bacterium from anoxic sediments of a freshwater lake. Int. J. Syst. Bacteriol. 46 (1), 183-188

Guo, Y., Gong, H., Guo, X., 2015. Rhizosphere bacterial community of Typha angustifolia L. and water quality in a river wetland supplied with reclaimed water. Appl. Microbiol. Biotechnol. 99 (6), 2883-2893.

Hernandez-Raquet, G., Budzinski, H., Caumette, P., Dabert, P., Le Ménach, K., Muyzer, G., et al., 2006. Molecular diversity studies of bacterial communities of oil polluted microbial mats from the Etang de Berre (France). FEMS Microbiol. Ecol. 58 (3), 550-562.

Heulin, T., Barakat, M., Christen, R., Lesourd, M., Sutra, L., De Luca, G., et al., 2003. Ramlibacter tataouinensis gen. nov., sp. nov., and Ramlibacter henchirensis sp. nov., cyst-producing bacteria isolated from subdesert soil in Tunisia. Int. J. Syst. Evol. Microbiol. 53 (2), 589-594.

Holmes, D.E., Nevin, K.P., Woodard, T.L., Peacock, A.D., Lovley, D.R., 2007. Prolixibacter bellariivorans gen. nov., sp. nov., a sugar-fermenting, psychrotolerant anaerobe of the phylum Bacteroidetes, isolated from a marine-sediment fuel cell. Int. J. Syst. Evol. Microbiol. 57 (4), 701-707.

Hougardy, A., Klemme, J.H., 1995. Nitrate reduction in a new strain of Rhodoferax fermentans. Arch. Microbiol. 164 (5), 358-362.

Jing, Y.X., Yang, D.J., 2004. Nitrogen removal and nitrogen-transformation bacteria of Cyperus alternifolius in constructed wetland. Ecol. Sci. 23 (1), 89-91.

Knapp, C.W., Lima, L., Susana, O.R., Emma, B., David, W., et al., 2012. Seasonal variations in antibiotic resistance gene transport in the Almendares River, Havana, Cuba. Front. Microbiol. 3, 396-417.

Kodama, Y., Watanabe, K., 2004. Sulfuricurvum kujiense gen. nov., sp. nov., a facultatively anaerobic, chemolithoautotrophic, sulfur-oxidizing bacterium isolated from an underground crude-oil storage cavity. Int. J. Syst. Evol. Microbiol. 54 (6), 2297-2300.

Lafortune, I., Juteau, P., Déziel, E., Lépine, F., Beaudet, R., Villemur, R., 2009. Bacterial diversity of a consortium degrading high-molecular-weight polycyclic aromatic hydrocarbons in a two-liquid phase biosystem. Microb. Ecol. 57 (3), 455-468.

LaMontagne, M.G., Schimel, J.P., Holden, P.A., 2003. Comparison of subsurface and surface soil bacterial communities in California grassland as assessed by terminal restriction fragment length polymorphisms of PCR-amplified 16S rRNA genes. Microb. Ecol. 46, 216-227.

Li, Z.M., 2012. Research advances of constructed wetland. J. Green Sci. Technol. 6, 151-154.

Li, B., Wang, X., Chen, R., Huangfu, W., Xie, G., 2008. Antibacterial activity of chitosan solution against Xanthomonas pathogenic bacteria isolated from Euphorbia pulcherrima. Carbohydr. Polym. 72 (2), 287-292.

Li, Y.H., Liu, Q.F., Liu, Y., Zhu, J.N., Zhang, Q., 2011. Endophytic bacterial diversity in roots of Typha angustifolia L. in the constructed Beijing Cuihu Wetland (China). Res. Microbiol. 162 (2), 124-131.

Lingens, F., Blecher, R., Blecher, H., Blobel, F., Eberspächer, J., Fröhner, C., et al., 1985. Phenylobacterium immobile gen. nov., sp. nov., a Gram-negative bacterium that degrades the herbicide chloridazon. Int. J. Syst. Evol. Microbiol. 35 (1), 26-39.

Liu, J., Wu, W., Chen, C., Sun, F., Chen, Y., 2011. Prokaryotic diversity, composition structure, and phylogenetic analysis of microbial communities in leachate sediment ecosystems. Appl. Microbiol. Biotechnol. 91 (6), 1659-1675.

Lovley, D.R., Giovannoni, S.J., White, D.C., Champine, J.E., Phillips, E.J.P., Gorby, Y.A., et al., 1993. Geobacter metallireducens gen. nov. sp. nov., a microorganism capable of coupling the complete oxidation of organic compounds to the reduction of iron and other metals. Arch. Microbiol. 159 (4), 336-344.

Ma, D.S., Xiong, W., Zhang, Q.Q., Guo, Y.H., Zhao, W.J., Guo, X.Y., 2014. The research of cattail rhizosphere bacteria community based on T-RFLP and FA. China Environ. Sci. 34 (10), 2684-2691.

Marsh, T.L., 1999. Terminal restriction fragment length polymorphism (T-RFLP): an emerging method for characterizing diversity among homologous populations of amplification products. Curr. Opin. Microbiol. 2 (3), 323-327.

Meng, Q.Y., Wu, X.H., Zhao, L.X., Liao, R.H., 2011. Water quality variations and improvement measures of reclaimed water reuse in scenic water in Beijing. Water Resour. Prot. 27, 1004-6933.

Nicomrat, D., Dick, W.A., Dopson, M., Tuovinen, O.H., 2008. Bacterial phylogenetic diversity in a constructed wetland system treating acid coal mine drainage. Soil Biol. Biochem. 40, 312-321.

Pfennig, N., 1978. Rhodocyclus purpureus gen. nov. and sp. nov., a ring-shaped, vitamin B12-requiring member of the family Rhodospirillaceae. Int. J. Syst. Evol. Microbiol. 28 (2), 283-288.

Proia, L., Osorio, V., Soley, S., Köck-Schulmeyera, M., Pérezb, S., Barcelób, D., Romanía, A.M., Sabatera, S., 2013. Effects of pesticides and pharmaceuticals on biofilms in a highly impacted river. Environ. Pollut. 178, 220-228.

Regier, N., Frey, B., Converse, B., Roden, E., Grosse-Honebrick, A., Bravo, A.G., et al., 2012. Effect of Elodea nuttallii roots on bacterial communities and $\mathrm{mm} \mathrm{Hg}$ proportion in a $\mathrm{Hg}$ polluted sediment. PLoS One 7 (9), e45565.

Riviere, D., Desvignes, V., Pelletier, E., Pelletier, E., Chaussonnerie, S., Guermazi, S., et al., 2009. Towards the definition of a core of microorganisms involved in anaerobic digestion of sludge. ISME J. 3 (6), 700-714.

Sambrook, J.F., Russell, D.W., 2001. Molecular Cloning: A Laboratory Manual. Cold Spring Harbor, p. 2100.

Schloss, P.D., Westcott, S.L., Ryabin, T., Hall, J.R., Hartmann, M., Hollister, E.B., et al., 2009. Introducing mothur: opensource, platform-independent, community-supported software for describing and comparing microbial communities. Appl. Environ. Microbiol. 75 (23), 7537-7541.

Stottmeister, U., Wießner, A., Kuschk, P., Kappelmeyer, U., Kästner, M., Bederski, O., et al., 2003. Effects of plants and microorganisms in constructed wetlands for wastewater treatment. Biotechnol. Adv. 22 (1), 93-117.

Sullam, K.E., Essinger, S.D., Lozupone, C.A., O'Connor, M.P., Rosen, G.L., Knight, R., et al., 2012. Environmental and ecological factors that shape the gut bacterial communities of fish: a meta-analysis. Mol. Ecol. 21 (13), 3363-3378.

Thurston, J.A., Foster, K.E., Karpiscak, M.M., Gerba, C.P., 2001. Fate of indicator microorganisms, giardia and cryptosporidium in subsurface flow constructed wetlands. Water Res. 35 (6), 1547-1551.

Tong, J., Wei, Y.S., 2012. State-of-the-art removal of antibiotic resistance bacteria (ARB) and antibiotic resistance gene (ARG) in wastewater treatment plants (WWTPs). Acta Sci. Circumst. 32 (11), 2650-2659.

Toyama, T., Sato, Y., Inoue, D., Sei, K., Chang, Y.C., Kikuchi, S., et al., 2009. Biodegradation of bisphenol $\mathrm{A}$ and bisphenol $\mathrm{F}$ in the rhizosphere sediment of Phragmites australis. J. Biosci. Bioeng. 108 (2), 147-150.

Toze, S., 2006. Reuse of effluent water-benefits and risks. Agric. Water Manag. 80 (1), 147-159. 
Truu, M., Juhanson, J., Truu, J., 2009. Microbial biomass, activity and community composition in constructed wetlands. Sci. Total Environ. 407 (13), 3958-3971.

Vierheilig, J., Frick, C., Mayer, R.E., Kirschner, A.K.T., Reischer, G.H., Derx, J., et al., 2013. Clostridium perfringens is not suitable for the indication of fecal pollution from ruminant wildlife but is associated with excreta from nonherbivorous animals and human sewage. Appl. Environ. Microbiol. 79 (16), 5089-5092.

Visser, J.M., de Jong, G.A.H., Robertson, L.A., Kuenen, J.G., 1997. A novel membrane-bound flavocytochrome c sulfide dehydrogenase from the colourless sulfur bacterium Thiobacillus sp. W5. Arch. Microbiol. 167 (5), 295-301.

Wakelin, S.A., Colloff, M.J., Kookana, R.S., 2008. Effect of wastewater treatment plant effluent on microbial function and community structure in the sediment of a freshwater stream with variable seasonal flow. Appl. Environ. Microbiol. 74 (9), 2659-2668.

Wang, J.J., Li, Y.M., Zhao, Z.W., Li, Q., Liu, Y.Z., Ye, C.J., et al., 2012. T-RFLP analysis of soil microbial community from Shandong province for forensic science. Adv. Mater. Res. 599, 250-253.

Wassen, M.J., Barendregt, A., Palczynski, A., de Smidt, J.T., de Mars, H., 1992. Hydro-ecological analysis of the Biebrza mire (Poland). Wetl. Ecol. Manag. 2 (3), 119-134.

Whitacre, D.M. (Ed.), 2012. Reviews of Environmental Contamination and Toxicology. Springer.

Winderl, C., Anneser, B., Griebler, C., Meckenstock, R.U., Lueders, T., 2008. Depth-resolved quantification of anaerobic toluene degraders and aquifer microbial community patterns in distinct redox zones of a tar oil contaminant plume. Appl. Environ. Microbiol. 74 (3), 792-801.

Xia, S., Jia, R., Feng, F., Xie, K., Li, H., Jing, D., Xu, X., 2012. Effect of solids retention time on antibiotics removal performance and microbial communities in an A/O-MBR process. Bioresour. Technol. 106, 36-43.
Xiang, X.M., Song, C.X., Li, Y.S., Sun, X.Y., 2004. Microorganism features of Typha latifolia and Phragmites australis at rhizosphere. J. Environ. Prot. Sci. 30 (4), 1004-6216.

Yang, Y., Wang, X., Shi, J., Li, J., 2012. The influence of the discharging sewage on microbial diversity in sludge from Dongting Lake. World J. Microbiol. Biotechnol. 28 (2), 421-430.

Yoshida, M., Ishii, S., Fujii, D., Otsuka, S., Senoo, K., 2012. Identification of active denitrifiers in rice paddy soil by DNA- and RNA-based analyses. Microbes Environ. 27 (4), 456-461.

Yu, S., Wang, M., Hong, Y.W., 2011. Antibiotics in environmental matrices and their effects on microbial ecosystems. Acta Ecol. Sin. 31 (15), 4437-4446.

Zhang, H., Zhang, X., Zhong, Y., 2007. Removal of oil in the lake in Daqing area using subsurface constructed wetland. Environ. Sci. 28 (7), 1449-1454.

Zhang, Y., Du, B.H., Jin, Z.G., Li, Z.H., Song, H.N., Ding, Y.Q., 2011. Analysis of bacterial communities in rhizosphere soil of healthy and diseased cotton (Gossypium sp.) at different plant growth stages. Plant Soil 339 (1-2), 447-455.

Zhao, Y.G., Ren, N.Q., Wang, A.J., Wan, C.L., 2007. Influence of organic pollutants on the bacterial community in Songhua River drainage area. Acta Microbiol Sin. 47 (2), 313-318.

Zhao, Y., Ren, N., Wang, A., 2008. Contributions of fermentative acidogenic bacteria and sulfate-reducing bacteria to lactate degradation and sulfate reduction. Chemosphere 72 (2), 233-242.

Zhou, L., Huo, Z.Y., Gan, Y.P., Zhou, J., Hao, E.C., Yao, Y., 2006. Benefit analysis of taking secondary effluent as landscape runoff source and cooling water. Environ. Eng. 24 (5), 16-18. 